\title{
Práticas de cuidado e população em situação de rua: o caso do Consultório na Rua
}

\author{
Care practices and homeless population: the street clinic case
}

Carolina Cruz da Silva1, Marly Marques da Cruz², Eliane Portes Vargas³

RESUMO O estudo visa compreender as práticas de cuidado de um Consultório na Rua, em Manguinhos/RJ, de forma a contribuir com o debate da Atenção Primária à Saúde para populações específicas. Trata-se de estudo de caso, tendo por procedimentos metodológicos: análise documental, observação direta, entrevistas com profissionais e representante do movimento social. Os resultados apontam para a construção de vínculos e para o rompimento com uma lógica prescritiva, prevalecendo uma escuta qualificada. Os profissionais exprimiram existir ainda resistências em atender a população em situação de rua, comumente associada a imagens estigmatizantes, que expressam os desafios na garantia do acesso desta população ao SUS.

PALAVRAS-CHAVE Atenção Primária à Saúde; População em situação de rua; Saúde da família.

ABSTRACT The study aims to understand the care practices of the Consultorio na Rua (street clinic) in Manguinhos/RJ in order to contribute to the debate of the Primary Health Care focused on specific vulnerable populations. This case study used as methodological procedures: documental analysis, direct observation, interviews with professionals and the representative of the social movement. The results point to the construction of bonds and the break with a prescriptive logic prevailing qualified listening. Professionals reported there were still resistance regarding health and social care towards homeless people, commonly associated with stigmatizing images that express one of the challenges in ensuring access of this population to the public health system.

KEYWORDS Primary Health Care; Homeless people; Family health.

\footnotetext{
1 Secretaria Municipal de Saúde do Rio de Janeiro Rio de Janeiro (RJ), Brasil. asccscarol@gmail.com

2 Fundação Oswaldo Cruz (Fiocruz), Escola Nacional de Saúde Pública Sergio Aroca (Ensp) - Rio de Janeiro (RJ), Brasil. marly@ensp.fiocruz.br

3 Fundação Oswaldo Cruz (Fiocruz), Instituto Oswaldo Cruz (IOC) - Rio de Janeiro (RJ), Brasil. epvargas@ioc.fiocruz.br
} 


\section{Introdução}

A categoria cuidado tem sido significativamente discutida no campo da saúde pública no Brasil por diversos autores, como Mehry (2004), Pinheiro e Mattos (2008) e Ayres (2009), quando apontam a complexidade que permeia as práticas a ela relacionada. $\mathrm{Na}$ visão destes autores, o cuidado à saúde relacionado ao ato de cuidar diz respeito a

uma interação entre dois ou mais sujeitos, visando o alívio de um sofrimento, ou o alcance de um bem-estar, sempre mediada por saberes especificamente voltados para essa finalidade. (AYRES, 2009, P. 42).

No cuidado à saúde, portanto, encontra-se ressaltada uma perspectiva relacional entre os sujeitos: profissional de saúde e usuário. Sendo assim, cabe aos profissionais de saúde se

mobilizarem pela construção de um projeto político que qualifique o cuidado, transcendendo a sua dimensão instrumental, o que se viabiliza quando, além do aumento da oferta de serviços e da resolubilidade de ações técnicas, exercita-se a escuta sensível de necessidades, praticando-se um acolhimento que valorize singularidades articuladas à totalidade. (COELHO; FONSECA, 2005, P. 216).

Faz-se necessário considerar a importância do cuidado não só no contexto do Sistema Único de Saúde (SUS) brasileiro, mas também no cenário internacional, no acesso à atenção e aos serviços oferecidos pelo sistema, prioritariamente pela Atenção Primária à Saúde (APS). A Estratégia Saúde da Família (ESF) tem contribuído para o campo da APS no Brasil, sendo a diretriz de vínculo entre a equipe, usuário, família e comunidade uma das principais norteadoras de mudança do modelo assistencial. Esta vem se contrapor a um processo de trabalho caracterizado tradicionalmente pela centralidade em programas de saúde e fragmentação pela lógica do especialista. Dentro de uma nova concepção, as Equipes da Saúde da Família (EqSF) deveriam, em tese, estar atreladas à orientação 'centrado nos usuários', em contraposição à lógica do 'centrado nos procedimentos' (MEHRY, 2004). Cabe destacar que esta opção pressupõe o aumento da capacidade reflexiva de cuidar voltada para as necessidades dos usuários 'do' e 'no' território. No entanto, mesmo com novas formas de produzir saúde, por meio desta estratégia consolidada a partir dos enfoques nos núcleos familiares e no território, a ESF ainda reproduz, em alguns casos, o cuidado com atos 'medicocêntricos', ou seja, centrados na atuação médica, estruturados por atos prescritivos (MEHRY, 2005).

Nessa perspectiva, a categoria cuidado expressa a complexidade da sua efetivação na atenção à saúde, uma vez que esta não se dá apenas por prescrições, medicalização, ou normatizações de condutas reduzidas a procedimentos e/ou protocolos. Isso porque, mais do que prescrever exames e medicamentos, os profissionais de saúde na atenção primária devem estar abertos ao diálogo com os usuários do serviço, aos seus desejos, às suas histórias, angústia e desafios, que são elementos constitutivos no projeto de vida destes. Tal perspectiva visa romper com uma proposição fragmentada do atendimento e pouco atenta aos aspectos psicossociais do adoecimento (AYRES, 2009). Torna-se, portanto, importante ressaltar que a resolutividade na rede básica de saúde está ligada não só ao recurso instrumental e conhecimento técnico dos profissionais, mas também à ação acolhedora, ao vínculo que se estabelece com o usuário, ao significado que se dá na relação profissional/usuário, que surge do "encontro de sujeitos com o sentido de atuar sobre o campo da saúde" (MERHY, 2002, P. 189).

A questão que se coloca no presente estudo é como garantir, além do acesso, esse cuidado para as populações em situação de vulnerabilidade extrema, como a População em Situação de Rua (PSR)? 
Embora o Brasil tenha avançado no acesso aos serviços de saúde por meio da expansão da cobertura pelas EqSF nos diversos municípios do País, ainda existem grupos que, devido à organização dos serviços e seus modos de vida, encontram grande dificuldade de acesso a estes serviços em decorrência de suas singularidades (CARNEIRO JUNIOR ET AL., 2010). Esse é o caso das pessoas em situação de vulnerabilidade, o que requer constante renovação dos arranjos e das metodologias de organização do cuidado. Destacam-se nesse grupo as pessoas que vivem em situação de rua que, historicamente, tem acesso limitado aos serviços de saúde com uma gama de entraves, alguns destes assinalados por Costa (2005): a exigência de comprovação de residência, tratamentos de saúde aplicados a regras que não levam em consideração as condições de vida destes indivíduos, e o despreparo dos profissionais para o acolhimento a esse grupo.

Recentemente, a Política Nacional de Atenção Básica instituiu os Consultórios na Rua (CRs) com o objetivo de ampliar o acesso dos usuários à rede de serviços de saúde (BRASIL, 2012A). A proposta das equipes do CR consiste em promover uma articulação da rede com a principal finalidade de garantir o acesso à atenção integral à saúde às pessoas em situação de rua/usuários de álcool e outras drogas. Algumas experiências brasileiras, como as de Belo Horizonte, São Paulo e Porto Alegre (COSTA, 2005) e Salvador (OLIVEIRA, 2009), vêm se destacando no atendimento à PSR, especificamente na atuação das EqSF, criadas para desenvolver ações de saúde no território da rua. Com o objetivo de caracterizar o perfil dessa população, foi realizada uma pesquisa pelo Ministério do Desenvolvimento Social, no ano de 2008, em metrópoles brasileiras, com exceção de São Paulo, Belo Horizonte, Recife e Porto Alegre. Os dados obtidos revelam que de um grupo de 31.922 pessoas, $82 \%$ eram homens e pouco mais da metade (52\%) entre 25 e 44 anos de idade. Com relação ao quesito raça/cor autodeclarado, 39,1\% eram pardos, $29,5 \%$ brancos e $27,9 \%$ negros. No total, $74 \%$ sabiam ler e escrever, e quase a metade (48,4\%) alegou ter completado o ensino fundamental. Os principais motivos pelos quais essas pessoas passaram a viver e morar na rua se referem aos problemas de alcoolismo e/ou drogas $(35,5 \%)$, ao desemprego $(29,8 \%)$ e $(29,1 \%)$ às desavenças com familiares (BRASIL, 2008).

Com base nas questões assinaladas, surgiu o interesse em estudar as práticas de cuidado no âmbito da atenção primária neste contexto específico de CR, no território de Manguinhos. As perguntas que orientaram esta investigação foram: Quais são as ações e práticas organizadas para o cuidado da população em situação de rua neste contexto? Como são desenvolvidas? Elas permitem a construção de vínculo?

Tendo em vista essas indagações, o objetivo do estudo consistiu em caracterizar como a equipe de CR da Clínica da Família Victor Valla (CFVV), em Manguinhos/RJ, desenvolve suas práticas de cuidado à saúde para a população em situação de rua. Ao considerar ainda a escassa produção de pesquisas sobre o tema, o intuito foi o de ampliar o conhecimento sobre práticas de cuidado acerca de um segmento tão discriminado e estigmatizado, bem como dar visibilidade a mais uma experiência inovadora no campo da saúde pública no contexto da rede de APS na cidade do Rio de Janeiro.

\section{Método}

Esta investigação se caracteriza como um estudo de caso apoiado na abordagem qualitativa, adequada para a problematização de questões muito particulares de objetos complexos (YIN, 2010).

O estudo, realizado como requisito parcial do mestrado em saúde pública realizado na Escola Nacional de Saúde Pública Sergio Arouca/Fiocruz (2011-2013), foi desenvolvido na cidade do Rio de Janeiro, no CR da CFVV, localizada no bairro de Manguinhos. A escolha dessa Unidade foi definida a partir 
de dois critérios: o primeiro, relacionado ao seu perfil caracterizado por ser destinado à atenção primária e funcionar segundo a lógica da ESF; o segundo, diz respeito ao fato da experiência de realização do CR ser recente no território de Manguinhos.

Verificou-se existirem diversos grupos de pessoas em termos das condições sociais, mas também quanto às diferentes cenas de ocupação nas ruas de Manguinhos: na linha do trem, nas vielas, nas avenidas principais. Nelas são encontradas pessoas dormindo, trabalhando com venda e coleta de lixo, utilizando drogas, fazendo higiene pessoal, alimentando-se etc. Algumas características desse grupo favorecem sua vulnerabilidade. Uma caracterização pode ser traçada com dados dos usuários atendidos, disponibilizados pela equipe do CR: $76 \%$ permanecem diariamente na região do estudo; concentram-se na faixa de 19 a 24 anos, sendo $39 \%$ mulheres e $61 \%$ homens; $53,1 \%$ são de cor parda e 33,9\% negra; $67 \%$ possui contato familiar esporádico; $96 \%$ informou o uso de algum tipo de droga; e $44 \%$ não possui documentação.

A descrição das práticas de cuidado do CR de Manguinhos tem por referência os atributos da atenção primária e a experiência da ESF. Por meio desta, buscou-se focalizar nas cenas de produção desse cuidado, nas ações dos profissionais no espaço da rua e no contexto de vulnerabilidade no qual se inserem as pessoas que vivem em situação de rua em Manguinhos. O trabalho de campo foi desenvolvido por uma das pesquisadoras-autoras, profissional de saúde com experiência na APS.

Para o desenvolvimento da pesquisa, foram utilizadas três técnicas para a coleta de dados, as duas primeiras aplicadas de julho a outubro de 2012: 'observação direta' das ações das cenas de cuidado desenvolvidas pelos profissionais diretamente no espaço da rua, 'entrevistas semiestruturadas' e 'levantamento de dados' secundários de informação. Foram utilizados roteiros para cada técnica: (1) de observação (infraestrutura; contexto organizacional; composição da equipe; rotina e dinâmica do atendimento: horário, porta de entrada, acolhimento, abordagem e estratégias de criação de vínculo e registro das informações); (2) de entrevista com profissionais de saúde (descrição das práticas de cuidado; experiência no e rotina do atendimento; estratégias de abordagem; registros de dados; redes de apoio identificadas e lições aprendidas); (3) de entrevista com um informante-chave representante do movimento social (mapeamento de dificuldades, problemas de saúde, acesso aos serviços de saúde e necessidade de vínculo), visando cotejar, em relação aos dados levantados, aspectos relacionados às demandas e necessidades dessa população e (4) roteiro de levantamento de dados (faixa etária, sexo, escolaridade, naturalidade, ocupação, formas de sustento; uso de álcool/ outras drogas, principais agravos de saúde identificados e acompanhados, tempo na rua, motivo de ida pra rua, relação com familiares) para caracterização do perfil dos usuários em prontuário, relatórios e fichas de cadastro. Esta descrição não será objeto de análise neste artigo. Complementarmente, utilizou-se um diário de campo para registro do trabalho de campo.

As entrevistas foram realizadas com os profissionais de saúde que atuam diretamente com a população em situação de rua, considerando o papel desempenhado por cada categoria profissional: agente comunitário de saúde, técnico de enfermagem, enfermeiro, médico, dentista, e profissionais de saúde mental. Estes pertencem à equipe de CR, com exceção de um que pertencia a outra equipe da CFVV. Foram entrevistados oito profissionais no espaço da educação permanente da Unidade e um informante-chave representante do movimento social. Para confidencialidade dos entrevistados, as entrevistas foram codificadas por numeração de modo que o sigilo, o nome e a identidade profissional fossem preservados.

$\mathrm{Na}$ análise das entrevistas, os relatos foram transcritos, organizados e relacionados aos dados da observação direta, o que tornou 
possível a descrição dos temas e tópicos relativos às práticas de cuidado na rua, levando-se em consideração as proposições iniciais do estudo. Nessa direção os resultados serão apresentados em torno de dois eixos interligados e separados apenas para efeito de apresentação: a coordenação e organização do cuidado; vínculo e acolhimento, ambos relativos especificamente ao cuidado na rua.

As entrevistas foram gravadas e armazenadas em local seguro, sob responsabilidade do pesquisador principal. O projeto foi aprovado pelo Comitê de Ética em Pesquisa da Escola Nacional de Saúde Pública Sergio Arouca/Ensp/Fiocruz, sendo o número de parecer 61.931.

\section{Resultados}

O olhar, neste estudo, voltou-se principalmente aos "microprocessos do trabalho em saúde" (FRANCO; MEHRY, 1999, P. 6), nos afazeres do cotidiano relativos à organização do cuidado em saúde, sobre os quais se observou o processo de acolhimento e o estabelecimento de vínculo da equipe do CR com seus usuários. De um ponto de vista teórico, cabe destacar que o ato de cuidar pode assumir diferentes significados e, particularmente, no caso das práticas de cuidado em saúde voltadas para a população em situação de rua, almeja-se que esteja relacionado à promoção de ações que garantam o princípio da equidade expresso no SUS.

As informações, impressões e dados que serão apresentados buscam, portanto, trazer à tona não somente questões que são enunciadas, mas também às vezes silenciadas pelos profissionais de saúde no seu cotidiano de trabalho, de modo a contribuir para a produção de práticas de cuidado inovadoras e coletivas no campo da APS, voltadas para populações específicas.

\section{A organização do cuidado na rua}

O CR, em sua concepção original, se constitui como uma das estratégias para o estabelecimento de elos de ligação entre o serviço de saúde e a população em situação de rua, sendo o encontro diretamente na rua um meio para a construção de vínculos que estimulem a ida dos usuários às unidades de saúde. No caso em questão, a cena do cuidado focalizada na pesquisa é a rua, sendo o planejamento organizado com foco no encontro com os usuários nas diversas cenas de uso de drogas no território. Assim, se o encontro entre profissionais da ESF e os usuários ocorre no domicílio e no serviço de saúde, no $\mathrm{CR}$ o encontro é na rua e em um único consultório localizado na CFVV. As ações na rua são focadas na redução de danos, que têm como característica principal "ofertar cuidado no espaço da rua” (BRASIL, 2012A). Nesse ponto, a prática se configura inicialmente no campo da intersubjetividade, traduzida nos encontros no espaço da rua que possibilitam a construção de vínculo entre os profissionais e os usuários, com vistas de construção de projetos terapêuticos.

Na observação direta das ações dos profissionais no espaço da rua, foi identificada uma atuação diversificada da equipe: realização de orientações sobre problemas de saúde, distribuição de insumos de prevenção de DST/Aids e explicação da proposta de trabalho da equipe do CR. Foi possível também presenciar, dependendo da situação de saúde apresentada no cuidado no espaço da rua, os profissionais convidando os usuários para irem à clínica, a fim de realizar o cuidado necessário.

A entrada da PSR na CFVV se apresentou como o segundo passo fundamental a ser galgado pela equipe para a continuidade do cuidado que, muitas vezes, se faz necessário no espaço físico do serviço. Em relação à utilização do espaço físico da CFVV, os informantes do estudo apontaram ter vivenciado inicialmente obstáculos descritos por um dos profissionais entrevistados (E4). Segundo ele, no início da utilização do serviço pelos usuários os demais profissionais da CFVV ficavam receosos, com medo e 
muito resistentes em receber as pessoas em situação de rua no serviço.

Os profissionais do CR relataram que um dos aspectos que favoreceram a entrada dos usuários no espaço físico da CFVV foi a disseminação de informações sobre o serviço entre os próprios usuários. Muitas vezes as PSR levavam seus colegas ao serviço quando estes precisavam de cuidado. A entrada desses usuários no serviço demonstrou para os demais profissionais da clínica, principalmente aqueles que acreditavam ser impossível cuidar dessa população, que o fato deles morarem nas ruas e utilizarem drogas não os impedia de procurar cuidado e de serem cuidados. Além disso, era recorrente entre profissionais o discurso de que cada usuário que chegava ao serviço estimulava a equipe a repensar suas estratégias, técnicas e procedimentos, com vistas à adequação para a realidade de vida dos usuários.

No entanto, a resistência em atender a PSR ainda era grande para alguns profissionais da CFVV, gerando como consequência a insegurança e/ou o medo da população em buscar o acesso ao serviço. Com a implantação do CR, observa-se que esse cenário tem se modificado, pois a equipe vinha utilizando como estratégia o diálogo com a PSR enfatizando, de acordo com um dos depoimentos, de que o acesso seria mais fácil e o atendimento mais rápido. Com isso, a incerteza de conseguir um atendimento de saúde vem sendo modificada paulatinamente com o vínculo que se estabelece no espaço da rua, nas cenas de uso de droga, além de se fortalecer no espaço da CFVV. Os usuários aos poucos foram se sentindo seguros com a referência de cuidado no espaço da clínica e passaram a frequentar a unidade, principalmente, de acordo com os profissionais, quando realmente as PSR sentiam muita dor, febre, ou alguma ferida que causava incômodo.

Durante o trabalho de campo, foi possível permanecer em diferentes horários e em ambos os turnos de funcionamento do serviço, na sala de espera da unidade ou, como muito profissionais a denominavam, no espaço do acolhimento. $\mathrm{O}$ turno da manhã era o de maior volume de recepção da população, e a maioria esperava o atendimento sentada. Alguns usuários aguardavam de pé para serem chamados pelos Agentes Comunitários de Saúde (ACS) nos guichês da unidade. Assim que era chamado, informava o seu local de moradia e, minimamente, o que buscava, fosse uma consulta agendada, uma consulta por demanda espontânea ou outra demanda. Depois de conversar com o ACS no guichê, os usuários esperavam um pouco mais para serem atendidos pela equipe de enfermagem ou médica. Por mais que houvesse muitas consultas marcadas, a maioria das demandas se apresentava de forma inesperada. $\mathrm{O}$ excesso desse tipo de demanda favorece um tipo de trabalho ambulatorial sem que haja por parte dos profissionais um conhecimento prévio e um acompanhamento da maioria dos usuários ao longo de seus itinerários terapêuticos, o que apresenta dificuldades em relação à integralidade do cuidado.

No caso da PSR, essa população adentra a CFVV com os profissionais ou por conta própria e é direcionada ou se direciona para a sala do consultório '10'. Em frente a este consultório, são encontrados bancos (longarinas) para recepcionar/acomodar as pessoas em situação de rua que procuram o serviço ou para serem levadas a ele pela equipe que diariamente vai ao encontro dos usuários nas cenas de uso de drogas. Ali é o espaço onde são realizadas as consultas dos diversos profissionais do CR. Esse é o principal espaço físico utilizado pelos usuários e pela equipe do CR onde diariamente atuam os profissionais da área de enfermagem e os ACS ou Agentes Sociais (AS).

Cabe assinalar que, para um dos profissionais da CFVV, a diferença, no âmbito da recepção/acolhimento da PSR, é vista como uma 'certa segregação', se comparado ao dos outros usuários. Na percepção de um dos profissionais de uma das EqSF da CFVV, havia dúvida se a escolha de separar o espaço 
do acolhimento seria o melhor caminho. Isso porque o usuário, ao chegar na clínica, ou se dirige para as cadeiras em frente ao consultório '10', ou é recepcionado pelo guarda, que, segundo o informante, tem uma abordagem especial, que o direciona para o local de atendimento até mesmo conduzindo-o diretamente à equipe e apresentando-o. Este atendimento especial, como descrito, não ocorre com os outros usuários.

\section{Vínculo e acolhimento}

As práticas de cuidado desenvolvidas pelo CR têm como eixo essencial a criação de vínculo, como atitude fundamental na realização do cuidar. Ou seja, buscam abrir mais espaço para os usuários como sujeitos, e não como objetos de intervenção, para uma maior capacidade da atenção e continuidade das ações no serviço, visando o atendimento às diferentes demandas de indivíduos (AYRES, 2009). Tal prática resulta na promoção de um efetivo envolvimento de profissionais e usuários, na perspectiva de resolução das demandas apresentadas, de acordo com o tempo e a necessidade da população. Se o profissional, em sua prática, atuar com posturas preconceituosas, buscando definir condutas que não condizem com a realidade de vida dessas pessoas, dificilmente o plano de cuidado proposto será realizado e, muito menos, a possibilidade de construção de vínculo vai ser efetivada.

$\mathrm{O}$ vínculo inicial da equipe do $\mathrm{CR}$ de Manguinhos estabelecido com as pessoas em situação de rua naquela região foi marcado nos primeiros momentos pelo constrangimento, pelo medo e, simultaneamente, pelo desejo de cuidado. O constrangimento, segundo relato da equipe, esteve associado ao fato dos usuários acharem que seriam rejeitados no espaço da clínica. O medo era derivado da contradição das políticas públicas, particularmente da Prefeitura/RJ, uma vez que o usuário por um lado era repreendido, recolhido por equipes de outras secretarias do município do Rio de Janeiro, e por outro, experimentava a oferta de acolhimento e cuidado pela equipe de saúde. Por fim, o desejo de ser cuidado pelos usuários foi aparecendo no decorrer das primeiras visitas às cenas de uso nesse território.

Com vistas à aproximação com os usuários, as estratégias utilizadas pelo CR no território foram diversas, sendo algumas delas assinaladas por um dos profissionais entrevistados: a mudança do jaleco do ACS, o uso apropriado da linguagem e uma postura para escutar e respeitar quando o usuário não quer aproximação. De acordo com o depoimento de uma profissional (E6), em algumas situações era necessário omitir para os usuários a categoria profissional de membros da equipe para que não fosse confundido com os profissionais da Secretaria Municipal de Assistência Social (SMAS), pois estes significavam para eles uma experiência negativa de atenção ao morador de rua. De forma processual, com o tempo e a persistência da equipe em atuar nas ruas, sempre com uma postura respeitosa e buscando a aproximação com base nas estratégias de redução de danos, os profissionais observaram que os usuários passaram 'a confiar e aceitar os serviços prestados pela equipe'.

A fim de prover um cuidado integral, a equipe estudada vem buscando cotidianamente mapear e conhecer a rede de proteção social e suas diversas instituições governamentais e não governamentais direcionadas à PSR. Realizam-se visitas às instituições para conhecer o funcionamento e rotinas e procuram-se relacionar os serviços mapeados ao perfil e às necessidades dos usuários. Essas ações contribuem para a construção de oferta de serviços mais qualificados pela equipe do $\mathrm{CR}$.

A entrevista com o representante do Fórum Estadual Permanente da PSR adulta foi reveladora no sentido de apontar os desafios de garantir o acesso desta população pelo SUS. Para ele, o Samu (Serviço de Atendimento Médico de Urgência) é um dos principais equipamentos de saúde, sendo que não está habilitado, no 
que se refere à sensibilidade e ao preparo, para lidar com este tipo de atendimento. Segundo esse informante, é importante um esforço de superação do abismo presente na relação entre os profissionais de saúde e a PSR sendo necessário o desprendimento dos profissionais de 'coisas pré-concebidas'.

\section{Discussão}

No que se refere à produção do cuidado, observa-se que a equipe do CR organizou seu processo de trabalho com certas particularidades no tocante às demais equipes da CFVV. Em primeiro lugar, destaca-se que houve adaptações das diretrizes da ESF, no que concerne à adscrição da clientela. As EqSF direcionam seu trabalho para a população cadastrada com domicílio fixo, o CR atende as pessoas no território da rua, sejam elas cadastradas ou não. Os procedimentos que eram denominados de forma diferenciada como 'visita domiciliar', passaram a ser 'visita de rua' (CARNEIRO JUNIOR ET AL,, 2010). A rotina de 'visita de rua' é diária, mas, diferentemente das outras EqSF da unidade, os profissionais do CR não concentram tais visitas majoritariamente nos ACS. Todos os profissionais têm agenda semanal, e para alguns quase diária, com vistas a fortalecer os vínculos e ampliação da acessibilidade de novos usuários à unidade.

Um profissional chamou a atenção ao assinalar que essa população era vista como 'bicho-papão'. Alguns relatos de discriminação por parte dos profissionais de saúde a essa população também foram descritos em outros trabalhos ao apontarem preconceitos e discriminações sofridas pela PSR nos serviços de saúde. Como exemplo, Canônico et al. (2007, P. 801) encontraram que as PSR questionavam o "preconceito por parte de equipes de saúde que resistiam em atendê-las, em decorrência de sua condição precária de higiene de saúde”.

Em segundo lugar, destaca-se o quantitativo de população cadastrada, em relação ao que é preconizado pela ESF. Segundo a Política Nacional de Atenção Básica (BRASIL, 2012B), uma
EqSF deve, em média, ter 3 mil cadastrados, chegando ao máximo de 4 mil pessoas cadastradas. Em contrapartida, uma equipe de CR deve se responsabilizar por um número de pessoas em situação de rua que varia de 80 a mil, conforme orientação descrita na regulamentação do Ministério da Saúde para os CRs (BRASIL, 2012A).

No período do trabalho de campo, foi relatado por um dos profissionais do CR que havia um total de 357 pessoas cadastradas. $\mathrm{O}$ quantitativo de pessoas estipulado pelo MS para o CR, que é de no máximo mil usuários, contribui significativamente com a construção de vínculo, com a possibilidade de respostas às necessidades de saúde da PSR (BRASIL, 2012C). No caso das EqSF, o elevado número de pessoas cadastradas vem sendo apontado como um desafio para a qualificação da ESF, sendo considerado o modelo de atenção ideal para pequenos municípios e não para os grandes centros urbanos (CONILL, 2008).

Em terceiro lugar considera-se o recorte territorial, isto é, a atuação do SF por ser bem diferente quanto ao espaço geográfico e seus limites, se comparada ao trabalho do CR, uma vez que a PSR apresenta grande mobilidade em relação à população cadastrada de Manguinhos. Sendo assim, não é possível delimitar o espaço de atuação por área ou microárea, como é realizado pelas EqSF. A equipe do CR é responsável pelo acompanhamento de todas as pessoas que se encontram em situação de rua no Território Integrado em Saúde (Teias) de Manguinhos, a qual muitas vezes ultrapassa o espaço geográfico do Teias para o acompanhamento de seus usuários.

Por último, cabe problematizar a proposta de cadastro dos usuários, na qual a equipe de CR propôs um modelo específico para essa população, em que o cadastramento era feito inicialmente na rua. Ocorre que após alguns meses de trabalho, os próprios usuários foram se colocando contrários a relatar particularidades de sua vida nas cenas de uso da droga. Também há uma preocupação em utilizar uma linguagem que deixe claras as ações e os 
procedimentos desenvolvidos na prática de cuidado realizada pelos profissionais.

As adequações particulares, ou dito de outro modo, os novos arranjos institucionais criados no processo de trabalho do CR ocorreram por conta das singularidades do 'modo de andar a vida' (CARNEIRO JUNIOR ET AL., 2010) das PSR, requerendo, constantemente, novos arranjos e metodologias de organização do cuidado. Conforme assinala Reis Junior (2011), a ausência de residência formal e o comportamento migratório inerente à PSR constituem especificidades nem sempre contempladas no trabalho das EqSF, restringindo, dessa forma, o acesso às populações que se organizam sem residência fixa, como, por exemplo, os ciganos.

Em relação à organização da equipe do CR, há uma ênfase no desenvolvimento de práticas coletivas e troca constante de saberes por parte dos profissionais, o que, para Passos e Barros (2000), pode ser definido por interseção, de conjugação de dois domínios na constituição de um terceiro, o que pode ser definido por interdisciplinaridade, ou seja, a criação de interseção entre os saberes e técnicas dos diversos profissionais. O espaço da reunião de equipe se apresenta como um espaço de educação permanente, sendo um "recurso estratégico para transformação das práticas e da própria organização do processo de trabalho" (CUNHA, 2010, $P$. 65). A integração dos saberes contribui para a construção de um projeto de cuidado para a PSR que abarque a complexidade e a multidimensionalidade das necessidades de saúde.

Do ponto de vista de mudança na lógica da produção do cuidado, foi possível perceber nitidamente que o cuidado ofertado pela equipe não é centrado na figura médica. Ao contrário, toda orientação do trabalho dos profissionais é centrada nas demandas e necessidades dos usuários, o que Franco, Bueno e Mehry (1999) denominam como um modelo de atenção 'usuário-centrada', até porque, diferentemente de outros usuários da unidade, a lógica prescritiva de condutas e medicamentos vai contra o estilo e modo de vida das pessoas em situação de rua.

\section{Considerações finais}

Esta pesquisa buscou caracterizar as práticas de cuidado em CR na APS, tendo como base a experiência desenvolvida na CFVV, localizada no território de Manguinhos/ RJ. Trata-se de uma experiência recente, que possibilitou uma reflexão sobre os necessários arranjos institucionais e organizacionais para a atenção e cuidado daqueles que vivem em situação de exclusão social na rua.

De acordo com os resultados da pesquisa, o cuidado com o usuário do $\mathrm{CR}$ não se restringiu apenas à equipe específica para este fim. Observou-se o envolvimento dos demais profissionais da CFVV, principalmente dos profissionais médicos que vêm demonstrando disponibilidade para o atendimento a essa população. O que se almeja é que o preconceito e o estigma diminuam a cada dia, na medida em que cuidar dessa população deixa de ser exclusividade do CR para fazer parte do caminho de comprometimento a ser construído por todos os profissionais da CFVV.

Nas cenas de cuidado no contexto do estudo, foram observadas singularidades da APS voltadas para uma população específica historicamente excluída do acesso aos serviços de saúde e demais políticas públicas. Destaca-se, nessa direção, ter havido uma maior flexibilidade da equipe do CR em Manguinhos em relação às normativas de organização e implementação, enquanto na EqSF prevalece a exigência do cumprimento de metas de produção de cadastro, procedimentos e acompanhamento de programas.

A organização de trabalho da equipe do CR demonstrou uma prática interdisciplinar, com processos constantes de troca de saberes e técnicas entre os profissionais da equipe. $\mathrm{O}$ reconhecimento da equipe como a referência em busca de cuidados por parte dos usuários tem conferido a ela, de fato, a condição de ordenadora das demandas dessa população 
para os demais serviços da rede, na medida em que procura resolver a maior parte das necessidades de seus usuários. As equipes específicas para o atendimento a PSR ainda não estão aprisionadas às exigências dos demais atendimentos, o que lhes possibilita construir um modelo alternativo de atenção, embora muitas vezes seja similar à proposta da ESF. Nessa direção, muitos são os avanços com a criação de uma equipe específica, mas não se pode afirmar que a ampliação do acesso esteja plenamente garantida. Estudos mais aprofundados são necessários para que se possa avaliar o surgimento nesse cenário desta categoria denominada 'equipe específica' em suas amplas dimensões.

$O$ que se apresentou no decorrer do estudo é que, a fim de prover um cuidado integral, a equipe do CFVV vem buscando cotidianamente mapear e conhecer a rede de proteção social e suas diversas instituições governamentais e não governamentais direcionadas à PSR. As ações voltadas ao reconhecimento do funcionamento de rotinas e mapeamento de serviços e perfil de modo a correlaciona-los às necessidades dos usuários contribuem para a construção de oferta de serviços mais qualificados pela equipe do CR. Pode-se perceber ainda que a equipe do
CR de Manguinhos demonstrou avanços na garantia do acesso a essa população específica, dirigido por uma equipe responsável pelo cuidado. Contudo, alguns desafios permanecem presentes no acesso a essa população como o seu cotidiano, tais como as regras de alguns serviços de saúde da rede e o preconceito ainda presente por parte de alguns profissionais da clínica, bem como a falta de Centro de Atenção Psicossocial Álcool e Drogas (Capsad) no território que se soma à falta de articulação da rede de atenção.

Cabe ressaltar, no entanto, que a proposta se apresenta de forma inovadora na cidade do Rio de Janeiro, na qual é desenvolvida, na medida em que parte das práticas de cuidado ocorre no contexto da rua. Com isso, o processo de trabalho da equipe traz elementos para o debate em torno das políticas públicas voltadas para a PSR, apresentando novos caminhos e horizontes que respeitem os direitos dessa população.

\section{Agradecimentos}

Agradecimento especial aos profissionais de saúde que atuam nos Consultórios na Rua da atenção básica em saúde, particularmente à equipe do território de Manguinhos.

\section{Referências}

AYRES, J. R. C. M. (Org.). Cuidado: trabalho e interação nas práticas de saúde. Rio de Janeiro: UERJ, 2009.

BRASIL. Ministério do Desenvolvimento Social e Combate à Fome. Secretaria de Avaliação e Gestão da Informação. Meta Instituto de Pesquisa de Opinião. Sumário Executivo: Pesquisa Nacional sobre a População em Situação de Rua. Brasília, DF: MDS, 2008.

Ministério da Saúde. Portaria $n^{\circ} 122$, de 25 de janeiro de 2011. Define as diretrizes de organização e funcionamento das Equipes de Consultório na Rua. Diário Oficial [da] República Federativa do
Brasil. Brasília, DF, 25 jan. 2012a. Disponível em: <http://bvsms.saude.gov.br/bvs/saudelegis/gm/2012/ prt0122_25_01_2012.html>. Acesso em: 2 mar. 2013.

Ministério da Saúde. Portaria $n^{\circ} 2.488$, de 21 de outubro de 2011. Aprova a Política Nacional de Atenção Básica, estabelecendo a revisão de diretrizes e normas para a organização da Atenção Básica, para a Estratégia Saúde da Família (ESF) e o Programa de Agentes Comunitários de Saúde (PACS). Diário Oficial [da] República Federativa do Brasil. Brasília, DF, 21 out. 2012b. Disponível em: <http://bvsms.saude.gov.br/bvs/ saudelegis/gm/2011/prt2488_21_10_2011.html>. Acesso em: 13 maio 2013. 
Ministério da Saúde. Secretaria de Atenção à Saúde. Departamento de Atenção Básica. Manual sobre o cuidado à saúde junto à população em situação de rua. Brasília, DF: Ministério da Saúde, 2012c. (Série A. Normas e Manuais Técnicos).

CANÔNICO, R. P. et al. Atendimento à população de rua em um Centro de Saúde Escola na cidade de São Paulo. Rev Esc Enferm USP, São Paulo, v. 41, n. spe., p. 799-803, 2007.

CARNEIRO JUNIOR, N. et al. A Estratégia Saúde da Família para a equidade de acesso dirigida à população em situação de rua em grandes centros urbanos. Saúde Soc., São Paulo, v. 19, n. 3, p. 709-716, 2010.

COELHO, E. A. C.; FONSECA, R. M. G. S . Pensando o cuidado na relação dialética entre sujeitos sociais. Rev Bras Enferm, Brasília, DF, v. 58, n. 2, p. 214-7, mar./abr. 2005

CONILL, E. M. Ensaio histórico-conceitual sobre a Atenção Primária à Saúde: desafios para a organização de serviços básicos e da Estratégia Saúde da Família em centros urbanos no Brasil. Cad. Saúde Pública, Rio de Janeiro, v. 24, supl. 1, p. s7-s16, 2008.

COSTA, A. P. M. População em situação de rua: contextualização e caracterização. Revista Virtual Textos e contextos, n. 4, dez. 2005. Disponível em: <http://revistaseletronicas.pucrs.br/fo/ojs/index.php/fass/article/ view/993/773>. Acesso em: 16 out. 2015.

CUNHA, M. S. O processo de trabalho em equipe e a produção do cuidado em saúde: desafios para a estratégia de saúde da família em Nova Iguaçu/RJ. 2010. 209 f. Dissertação (Mestrado e Saúde Pública) - Escola de Saúde Pública Sergio Arouca, Fundação Oswaldo Cruz, Rio de Janeiro, 2010.

FRANCO, T. B.; MEHRUY, E. E. PSF: contradições e novos desafios. Disponível em: <http://www.datasus. gov.br/cns/temas/tribuna/PsfTito.htm>. Acesso em: 2 mar. 1999.

FRANCO, T. B.; BUENO, W. S.; MEHRY. E. E. O acolhimento e os processos de trabalho em saúde: o caso de
Betim. Cad. Saúde pública, Rio de janeiro, v. 15, n. 2, p. 375-353, 1999.

MERHY, E. E. Saúde: a cartografia do trabalho vivo. São Paulo: Hucitec, 2002.

$\mathrm{O}$ ato de cuidar: a ama dos serviços de saúde. In: BRASIL. Ministério da Saúde. Secretaria de Gestão do Trabalho e da Educação na Saúde. Departamento de Gestão da Educação na Saúde. Ver - SUS Brasil: cadernos de textos. Brasília, DF: Ministério da Saúde, 2004, p. 108-137. (Série B. Textos Básicos de Saúde).

O desafio que a educação permanente tem em si: a pedagogia da implicação. Interface - comunicação, saúde, educação, São Paulo, v. 9, n. 16, p. 161-177, 2005.

OLIVEIRA, M. G. P. N. Consultório de Rua: Relato de uma Experiência. Salvador/BA. 2009. 15lf. Dissertação (Mestrado em Saúde Pública) - Instituto de Saúde Coletiva, Universidade Federal da Bahia, Salvador, 2009.

PASSOS, E.; BARROS, R. B. A construção do plano da clínica e o conceito de transdisciplinariedade. Brasília, DF: Psicologia: teoria e pesquisa, 2000.

PINHEIRO, R.; MATTOS, R. (Org.). Cuidado: as fronteiras da integralidade. 4. ed. São Paulo: Hucitec, Rio de Janeiro: Abrasco, 2008.

REIS JUNIOR, A. G. Estudo de caso da equipe de Saúde da Família para população em situação de rua de Belo Horizonte/MG. 2011. 128 f. Dissertação (Mestrado em Saúde Pública) - Escola de Saúde Pública Sergio Arouca, Fundação Oswaldo Cruz, Rio de Janeiro, 2011.

YIN, R. K. Estudo de caso: planejamento e métodos. Porto Alegre: Bookman, 2010.

Recebido para publicação em abril de 2015

Versão final em novembro de 2015

Conflito de interesses: inexistente

Suporte financeiro: não houve 